\title{
СОВРЕМЕННЫЕ ПОДХОДЫ К ХИРУРГИЧЕСКОМУ ЛЕЧЕНИЮ БОЛЬНЫХ РАКОМ ПИЩЕВОДА И КАРДИАЛЬНОГО ОТДЕЛА ЖЕЛУДКА
}

\author{
В. И. Стариков ${ }^{1}$, А. С. Ходак', В. В. Макаров ${ }^{1}$, Ю. В. Иванова ${ }^{2}$, А. Ю. Бодрова ${ }^{1}$ \\ ${ }^{1}$ Харьковский национальный медицинский университет, \\ ${ }^{2}$ Институт общей и неотложной хирургии имени В. Т. Зайцева НАМН Украины, г. Харьков

\section{MODERN APPROACHES TO SURGICAL TREATMENT OF PATIENTS, SUFFERING ESOPHAGEAL AND GASTRIC CARDIA CANCER}

\author{
V. I. Starikov ${ }^{1}$, A. S. Khodak', V. V. Makarov', Yu. V. Ivanova ${ }^{2}$, A. Yu. Bodrova ${ }^{1}$ \\ ${ }^{1}$ Kharkov National Medical University, \\ 2Zaytsev Institute of General and Urgent Surgery, Kharkov
}

\begin{abstract}
Реферат
Приведены результаты хирургического лечения 218 больных по поводу рака пищевода (РП) и кардиального отдела желудка (РКОЖ). Рассмотрены вопросы лимфодиссекции D2 без спленэктомии. Предложен новый вариант наложения пищеводно-желудочного анастомоза. Проанализированы послеоперационные осложнения, частота которых составила $34,9 \%$, преимущественно с поражением сердечно-сосудистой системы (15,1\%). После операции умерли $4(1,8 \%)$ больных.

Ключевые слова: рак пищевода; рак кардиального отдела желудка; лимфодиссекция; анастомоз; осложнения.

Abstract

Results of surgical treatment of 218 patients for esophageal and gastric cardia cancers are adduced. The issues of lymphodissection D2 without splenectomy were discussed. New variant of the esophago-gastric anastomosis formation was proposed. Postoperative morbidity was analyzed, its rate have constituted $34.9 \%$, predominantly with cardio-vascular system affection (15.1\%). After the operation $4(1.8 \%)$ patients died.

Keywords: esophageal cancer; gastric cardia cancer; lymphodissection; anastomosis; complications.
\end{abstract}

Лечение РП и РКОЖ представляет наиболее сложную проблему клинической онкологии. Основным методом, позволяющим достичь полного излечения больных, является хирургический. При этом показатели пятилетней выживаемости больных составляют 25 - 35\%, послеоперационная летальность при РП и РКОЖ - 10 - 12\%, частота послеоперационных осложнений - от 25 до 60\% в различных клиниках $[1,2]$. Большинство (50 - 60\%) оперированых больных умирают в сроки до 2 лет после операции от местного рецидива заболевания.

Сложность проблемы определяет анатомическое положение пищевода, его расположение рядом с сердцем, аортой, трахеей, бронхами, блуждающим нервом. Кроме того, расположение в трех анатомических зонах определяет особенности лимфогенного метастазирования опухолей пищевода.

Хирургия РП и РКОЖ - один из наиболее сложных и сравнительно молодых разделов онкологии. Поэ- тому существуют многочисленные вопросы, на решение которых имеются различные, иногда противоположные взгляды.

К таким вопросам относятся: выбор оптимального хирургического доступа по поводу рака различных частей пищевода и РКОЖ, объем лимфодиссекции, реконструктивный этап операции, отношение к спленэктомии, целесообразность проведения адъювантной лучевой терапии и химиотерапии.

Предметом дискуссии среди хирургов является целесообразность применения косого торакоабдоминального доступа с пересечением реберной дуги и рассечением диафрагмы при РКОЖ. Онкохирурги полагают, что только такой доступ обеспечивает выполнение радикального вмешательства с адекватной лимфодиссекцией и оптимальные условия для формирования пищеводно-желудочного анастомоза, а возможность осложнений, связанных с травматичностью доступа, преувеличена.
По данным патологоанатомического исследования умерших после резекции пищевода или проксимальной резекции желудка по поводу рака, неудаленные метастазы в лимфатических узлах средостения обнаружены у 25\%. В связи с этим необходима стандартизация методики выполнения профилактической лимфодиссекции зон регионарного метастазирования, которая является как лечебной, так и диагностической. В настоящее время хирургическое вмешательство у больных по поводу рака грудной части пищевода без выполнения лимфодиссекции не рассматривают в принципе как допустимый вариант лечения.

Ключевым этапом операции по поводу РП и РКОЖ является формирование пищеводно-желудочного или пищеводно-кишечного анастомоза. Оно сопровождается высокой (6-15\%) частотой несостоятельности швов анастомоза нередко с фатальным исходом.

Поскольку рак пищевода и желудка крайне редко метастазиру- 
ет в пульпу селезенки, возникает вопрос, целесообразно ли выполнение спленэктомии при технической возможности лимфодиссекции ворот селезенки. В настоящее время существует неоднозначное отношение к спленэктомии при РП и РКОЖ. Лимфодиссекция D2 предусматривает удаление парагастральных лимфатических узлов и узлов, расположенных вдоль чревного ствола (112 группы лимфатических узлов по классификации JGCA). Спленэктомия в такой ситуации признана обязательным этапом операции, ее выполняют именно в целях удаления лимфатических узлов ворот селезенки (10 группа по JGCA) [3]. В то же время, селезенка является частью ретикулоэндотелиальной системы, основным источником циркулирующих лимфоцитов, в ней разрушаются старые әритроциты и тромбоциты, она действует как фильтр для микроорганизмов и простейших, продуцирует антитела. После спленэктомии частота послеоперационных гнойно-септических осложнений, в частности, поддиафрагмального абсцесса, панкреатического свища, пневмонии может увеличиваться на $20 \%$.

\section{МАТЕРИАЛЫ И МЕТОДЫ ИССЛЕДОВАНИЯ}

Проанализированы результаты лечения 218 больных, у которых по поводу РП и РКОЖ выполнены резекция пищевода (операция Льюиса - у 87), проксимального отдела желудка с нижнегрудной частью пищевода (операция Осава - Гарлока - у 109), гастрэктомия с применением торакоабдоминального доступа (у 22).

\section{Структура послеоперационных осложнений}

\begin{tabular}{|lcc|}
\hline & \multicolumn{2}{c|}{ Число больных } \\
\cline { 2 - 3 } & абс. & $\%$ \\
\hline Нарушение ритма сердца & 29 & 13,3 \\
\hline Пневмония на стороне торакотомии & 26 & 11,9 \\
\hline Несостоятельность швов пищеводно-желудочного анастомоза & 5 & 2,3 \\
\hline Сердечная недостаточность & 4 & 1,8 \\
\hline Внутриплевральное кровотечение & 3 & 1,4 \\
\hline Кровотечение из культи желудка & 2 & 0,9 \\
\hline Ротация культи желудка & 1 & 0,5 \\
\hline Тромбоэмболия легочной артерии & 1 & 0,5 \\
\hline Прочие & 5 & 2,3 \\
\hline Всего ... & 76 & 34,9 \\
\hline
\end{tabular}

Мужчин было 180 (83\%), женщин - 38 (17\%). Заболевание в стадии T1-2N0M0 диагностировано у 50 (23\%) пациентов, T1-3N1-2M0 у 168 (77\%). У большинства больных отмечено поражение регионарных лимфатических узлов. По данным гистологического исследования, у 30 (65,4\%) больных диагностирован железистый рак, у 188 (34,6\%) плоскоклеточный. Возраст пациентов в среднем 63,7 года. У всех больных диагноз рака верифицирован морфологически до операции. У 39 (17,9\%) больных операции были комбинированные, сопровождались резекцией перикарда, легкого, левой доли печени, удалением селезенки, хвоста поджелудочной железы.

Операцию Льюиса начинали с правосторонней торакотомии и мобилизации грудной части пищевода с опухолью, затем выполняли лапаротомию, мобилизовали желудок с сохранением правой желудочносальниковой артерии. После формирования внутригрудного пищеводно-желудочного анастомоза и дренирования обе полости (грудную и брюшную) зашивали. Такая последовательность операции позволяла контролировать состояние трансплантата желудка при его перемещении в плевральную полость, что предотвращало его ротацию.

При операции Осава-Гарлока вначале вскрывали брюшную полость косым разрезом от пупка до хряща реберной дуги на уровне шестого межреберья слева. При установлении операбельности разрез продолжали, вскрывали грудную полость по шестому межреберью слева с пересечением реберной дуги и рассечением диафрагмы. 
операционных осложнений приведена в таблице.

Наиболее частыми были осложнения с поражением сердечно-сосудистой системы (15,1\%). Нарушения ритма сердца наиболее часто возникало на 2-3-и сутки после операции, как правило, его устраняли консервативными средствами. Высокую частоту аритмий мы объясняем расширением показаний к выполнению операции у больных пожилого возраста.

Пневмония при операции Льюиса возникала справа, при операции Осава-Гарлока - слева. Это свидетельствовало о необходимости раздельной интубации бронхов и выключения легкого на стороне операции в целях его минимальной механической травматизации.

у одного больного после операции Льюиса отмечена ротация желудочного интерпоната. Осложнение диагностировано на 7-е сутки при контрольном рентгенологическом исследовании. У пациента обнаружено отсутствие эвакуации водорастворимого контрастного вещества из культи желудка в кишечник. Произведена релапаротомия, разрушены сращения в области диафрагмального отверстия. Желудок атоничен, значительно увеличен, в нем содержалось большое количество жидкости. Установлена ротация интерпоната в пилородуоденальной зоне. Сформирован гастроэнтероанастомоз. Через 8 сут после второй операции пациент выписан по выздоровлении.

У 2 (0,9\%) больных кровотечение из острых эрозий культи желудка в зоне анастомоза диагностировано по данным эндоскопии. После консервативного лечения кровотечение остановлено.

После операции умерли 4 больных (летальность 1,8\%) от острой сердечной недостаточности.

Частота послеоперационных осложнений при РП и РКОЖ достаточно высока - 34,9\%. Особенностью современного периода является изменение спектра послеоперационных осложнений. Если раньше основным фатальным осложнением была несостоятельность швов анастомоза, сегодня это осложнение занимает одно из последних ранговых мест. В связи с расширением показаний к выполнению операции у па- циентов пожилого возраста при РП и РКОЖ выявляют сопутствующие заболевания на фоне отягощенного анамнеза и вредных привычек, алиментарное истощение, паранеопластические синдромы. Эти факторы определяют структуру осложнений и летальности. Ведущее место в структуре послеоперационных осложнений занимают терапевтические: сердечно-сосудистые и легочные, они составляют более 80\% всех осложнений. Наиболее частым сердечно-сосудистым осложнением является нарушение ритма сердца.

Способ формирования пищеводного анастомоза - это самостоятельная сторона проблемы. Поиски оптимального способа продолжаются. Однако, на наш взгляд, исход зависит не столько от использованного способа, сколько от его соответствия принципам правильности его технического выполнения и оптимального заживления анастомоза

Несмотря на сложность оперативных вмешательств и высокую частоту осложнений, хирургический метод остается ведущим в лечении РП и РКОЖ.

\section{ЛITEPATYPA/REFERENCES}

1. Afanasev SG, Avgustinovich AV, Tuzikov SA. Rezultaty rasshirennykh i kombinirovannykh operatsiy po povodu raka zheludka i kardioezofagealnogo perekhoda. Sibirskiy onkologicheskiy zhurnal. 2011;(6):36-41. [In Russian].

2. Ganul VL, Kirkilevskiy SI, Kondratskiy YUN. Kombinirovannyy torako-abdominalnyy dostup - metod vybora pri operatsiyakh po povodu raka zheludka s rasprostraneniem na pishchevod. Klinicheskaya onkologiya. 2013;(1):6-9. [In Russian].

3. Bumm R, Wong J. More or less surgery for esophageal cancer: extent of lymphadenectomy in esophagectomy for squamous cells esophageal carcinoma: How much is necessary. Diseases of the Esophagus. 1994;(7):151-5.
4. D'journo XB, Thomas PA. Current management of esophageal cancer. J Thorac Dis. 2014;(6):253-64.

5. Metzger R, Schütze F, Monig S. Evidence-based operative details in esophageal cancer treatment: Surgical approach, lymphadenectomy, anastomosis. Viszeralmedizini. 2015; 337-40.

6. Rizk NH, Ishwaran H, Rice TW. Optimum lymphadenectomy for esophageal cancer. Annals Surgery. 2010;(251):46-50. 